https://helda.helsinki.fi

\title{
Tardy development of safe medicines for children : a Nordic network offers new platform to reduce this inequity
}

\section{Naumburg, Estelle}

2019-06

Naumburg , E, Rane , A , Halvorsen , T , Glosli , H, Henriksen , T B , Haraldsson , A, Kallio , J \& Lepola , P 2019 , ' Tardy development of safe medicines for children : a Nordic network offers new platform to reduce this inequity ' , Acta Paediatrica , vol. 108 , no. 6 , pp. 992-993 . https://doi.org/10.1111/apa.14775

http://hdl.handle.net/10138/303516

https://doi.org/10.1111/apa.14775

publishedVersion

Downloaded from Helda, University of Helsinki institutional repository.

This is an electronic reprint of the original article.

This reprint may differ from the original in pagination and typographic detail.

Please cite the original version. 


\title{
Tardy development of safe medicines for children: a Nordic network offers new platform to reduce this inequity
}

\author{
Estelle Naumburg (estelle.naumburg@umu.se) ${ }^{1,2}$ (D) Anders Rane ${ }^{2}$ (D) , Thomas Halvorsen ${ }^{3,4}$, Heidi Gloslil ${ }^{5}$, Tine Brink Henriksen ${ }^{6}$, \\ Àsgeir Haraldsson ${ }^{7}$, Jaana Kallio ${ }^{8}$, Pirkko Lepola ${ }^{8}$ \\ 1.Department of Clinical Science, Paediatrics, Umeå University, Umeå, Sweden \\ 2.Division of Clinical Pharmacology, Karolinska Institutet, Karolinska University Hospital (Huddinge site), Stockholm, Sweden \\ 3.Department of Clinical Science, University of Bergen, Bergen, Norway \\ 4.Department of Paediatrics, Haukeland University Hospital, Bergen, Norway \\ 5.Institute for Paediatric Research, Division of Paediatric and Adolescent Medicine, Oslo University Hospital, Oslo, Norway \\ 6.Perinatal Epidemiology Research Unit, Deptartment of Paediatric and Adolescent Medicine, Aahus University Hospital, Aahus, Denmark \\ 7.Faculty of Medicine, Children's Hospital, University of Iceland, Landspítali - University Hospital, Reykjavik, Iceland \\ 8.Department of Children and Adolescents, Helsinki University Hospital, Helsinki, Finland
}

\author{
Correspondence \\ Dr E Naumburg, Barn- och ungdomskliniken \\ Östersunds sjukhus, 83183 Östersund, Sweden. \\ Tel: +46708173578 \\ Fax: +46-63154523 | \\ Email: estelle.naumburg@umu.se
}

DOI:10.1111/apa.14775

Less than $30 \%$ of all marketed drugs worldwide have a paediatric licensing, and $<50 \%$ of all marketed drugs are registered for children; in neonates less than $10 \%(1,2)$. This is not a fair situation since children should have the same right and access to tested medicines as adults. Even so, we see that off-label drugs are increasingly prescribed to children of all ages. This is evident from official sales statistics including many drugs used in areas such as child psychiatry, neurology, cardiology and more (3). Prescriptions of important drugs to these and other therapeutic areas often depend on experience-based knowledge and sometimes on poor evidence.

Children differ from adults with respect to body size, maturation of organs, body composition, psychology, parental dependency, just to mention a few important features, making the execution of the paediatric pharmacotherapy more challenging in healthcare practice (4). Lack of clinical studies are not the only reason for a medicine being off-label. It is a quite common situation that pharmaceutical companies research on medicines for children are not completed, or fail to put the product on the market, maybe due to lack of profit, leaving paediatricians to have no other choice but use these in off-label manner $(5,6)$. The current use of unlicensed and insufficiently studied medicines in neonates, children and adolescents, increases the risk of facing unexpected adverse drug reactions related to administration and dosage, but also for the administration of too low exposures with insufficient efficacy $(5,7)$.

The EU Paediatric Regulation came into force in January 2007 and included a requirement that the pharmaceutical companies include paediatric trials into their drug development pipelines (8), if necessary in the form of a Paediatric Investigation Plan. In exchange, it included also an incentive in the form of a product patent prolongation of up to six months.

After 10 years, the EU Paediatric Regulation was evaluated by the European Medicines Agency (EMA). This 10year evaluation report concluded that the Regulation had facilitated the development of paediatric medicines, information and accessibility of medicines for use in children. However, some concerns were raised. The report summarised that legislative measures are necessary to correct the inequalities relating to access to safe and effective medicines for children, but paediatric studies may be delayed or not initiated. This was explained by the recruitment difficulties of children into clinical trials, and by poor research on off-patent products. Further stated, the lack of research infrastructure had been identified, and EU coordinated action was suggested to relieve that situation. An important conclusion in the report was that the research incited by the regulation was not driven by real paediatric clinical needs, but by adult medicine development and economic incentives $(6,9)$.

Paediatric oncology is currently the only paediatric subspecialty with an increase in the number of clinical trials and with a comparable number of academic and industry sponsored trials. In the Nordic area, this is linked to a strong and long-term academic collaboration within the Nordic Society of Paediatric Haematology and Oncology, clearly underlining the value of a Nordic network (10). Further, an evaluation 


\begin{tabular}{|c|c|c|}
\hline Country & Name & Web-address \\
\hline $\begin{array}{l}\text { The Nordic } \\
\text { countries }\end{array}$ & NordicPedMed & https://www.nordicpedmed.com/ \\
\hline Finland & FinPedMed & http://www.finpedmed.com \\
\hline Denmark & DanPedMed & $\begin{array}{l}\text { http://www.clinicaltrialsdenmark.com/wha } \\
\text { t-do-we-offer/clinical-research-networks/ } \\
\text { danpedmed-danish-pediatric-research-ne } \\
\text { twork }\end{array}$ \\
\hline Norway & NorPedMed & $\begin{array}{l}\text { https://www.legemidlertilbarn.no/f } \\
\text { orskning/Sider/Medicines-for-Children-Re } \\
\text { search-Network-Norway.aspx }\end{array}$ \\
\hline Iceland & IcePedMed & $\begin{array}{l}\text { https://www.landspitali.is/sjuklingar-adsta } \\
\text { ndendur/deildir-og-thjonusta/barnaspitali- } \\
\text { hringsins/ }\end{array}$ \\
\hline Sweden & SwedPedMed & http://www.swedpedmed.se/ \\
\hline
\end{tabular}

and follow-up of treatments is equally important. We find that it is now time for children with other medical conditions to become subject to a similar type of Nordic collaboration, promoting development of safe medicines in all paediatric areas. Such collaboration will give room to pursue ethical, cost/effective and conclusive clinical drug trials to address the unmet needs of evidence-based medicines for neonates, children and young people, and a solid network for follow-up of drug treatment.

This may be achieved by collaboration between the five Nordic countries with altogether more than five million children and comparable to most European countries. The strengths of the Nordic area in a research context are many, including similar public paediatric health services, and advanced registries on health care using personal identification numbers and nationwide Healthcare Quality Registries and Governmental Registers. To this end, a NORDIC investigators network for PEDiatric MEDicines (NordicPedMed) was established between the years 2014 and 2017 with funding of a three-year Nordic Trial Alliance project from the Nordic Council of Ministers and NordForsk. It is an independent collaborative, academic, Nordic network giving expert advice, answering fast feasibility requests throughout the network on all different fields of neonatal and other paediatric sub-specialities, and conducting paediatric clinical trials (Table 1). NordicPedMed is a non-legal entity, nonregulatory, non-profit umbrella network of experts of five individual national paediatric clinical trial networks. The network offers a relatively uniform arena for Nordic collaboration and good options to achieve the aforementioned goals. NordicPedMed has processed fast industrial feasibility requests as well medical expert advice. The network aims to improve the collaboration and support academic as well as industrial clinical trials in children and neonates. NordicPedMed is one of the many similar research networks in Europe, and part of the Enpr-EMA network (11).

The authors acknowledge the increasing understanding of the need for sound and reliable research for medicines used in children. Nevertheless, these studies have until now been driven primarily by the pharmaceutical industry. More can be done. NordicPedMed calls for extensive, combined and collaborative efforts, involving industry, governmental agencies and academic institutions to further enhance studies in the area of paediatric medicines. The NordicPedMed looks forward to this cooperation.

\section{FUNDING}

This overview of the current situation on paediatric medicine development in Nordic countries has been prepared by authors without any additional funding for this particular purpose over the national networks' own operational funding.

\section{CONFLICT OF INTEREST}

The authors have no conflicts of interest to declare.

\section{References}

1. Conroy S, Choonara I, Impicciatore P, Mohn A, Arnell H, Rane A, et al. Survey of unlicensed and off label drug use in paediatric wards in European countries. European Network for Drug Investigation in Children. BMJ 2000; 320: 79-82.

2. Kimland ENP, Odlind V, Bottiger Y, Lindemalm S. Paediatric drug use with focus on off-label prescriptions at Swedish hospitals - a nationwide study. Acta Paediatr 2012; 101: 772-8.

3. Socialstyrelsen. Läkemedelsregistret. Available at http:// www.socialstyrelsen.se/statistik/statistikdatabas/lakemede 12017. (accessed on October 1, 2018).

4. Yaffe S, Aranda J. Neonatal and pediatric pharmacology. 3rd ed. Philadephia, PN: Lippincot Williams and Wilkins, 2005.

5. Nordenmalm S, Tomasi P, Pallidis C. More medicines for children: impact of the EU paediatric regulation. Arch Dis Child 2018; 103: 557-64.

6. EMA. 10-year Report to the European Commission General report on the experience acquired as a result of the application of the Paediatric Regulation. Available at https://ec.europa.eu/ health/sites/health/files/files/paediatrics/2016_pc_report_ 2017/ema_10_year_report_for_consultation.pdf; 2016. (accessed on June 10, 2018).

7. Bellis JR, Kirkham J, Thiesen S, Conroy EJ, Bracken LE, Mannix HL, et al. Adverse drug reactions and off-label and unlicensed medicines in children: a nested case-control study of inpatients in a pediatric hospital. BMC Med 2013; 11: 238.

8. Regulation (EC) No 1901/2006 of the European Parliament and of the Council of 12 December 2006 on medicinal products for paediatric use and amending Regulation (EEC) No 1768/ 92, Directive 2001/20/EC, Directive 2001/83/EC and Regulation (EC) No 726/2004; 2006.

9. EMA. Needs for paediatric medicines. Available at https:// www.ema.europa.eu/human-regulatory/research-developme nt/paediatric-medicines/needs-paediatric-medicines: EMA. (accessed on October 1, 2018).

10. NOPHO. Nordic Society of Paediatric Haematology and Oncology. Available at http://www.nopho.org/welcome/ frame.htm (accessed on October 1, 2018)

11. Ruperto N, Eichler I, Herold R, Vassal G, Giaquinto C, Hjorth L, et al. A European Network of Paediatric Research at the European Medicines Agency (Enpr-EMA). Arch Dis Child 2012; 97: 185-8. 